03;09

\title{
Диагностика наличия твердых частиц в каплях водяного аэрозоля по их интерференционной картине
}

\author{
(C) Р.С. Волков, С.В. Чванов, Д.Д. Андриянов \\ Национальный исследовательский Томский политехнический университет, \\ Томск, Россия \\ E-mail: romanvolkov@tpu.ru
}

Поступило в Редакцию 28 февраля 2019г.

В окончательной редакции 28 февраля 2019 г.

Принято к публикации 25 марта 2019г.

Представлены результаты экспериментальных исследований по определению влияния твердых частиц в каплях водяного аэрозоля на интерференционную картину последних. Для создания интерференционной картины использованы импульсный $\mathrm{Nd}$ : YAG-лазер и CCD-видеокамера. Радиусы капель водяного аэрозоля составляли 10-140 $\mu \mathrm{m}$. Использованы четыре вида твердых частиц с массовой концентрацией $0.003-1 \mathrm{~g} / 1$. Выделены специфические типы интерференционных картин, обусловленные наличием в капле примеси. Установлено влияние типа и концентрации примеси на интегральные характеристики интерференционных картин (количество и вид). Предложен подход для определения концентрации и размеров частиц примеси, основанный на анализе интерференционных картин.

Ключевые слова: капля, аэрозоль, примеси, интерференционная картина.

DOI: 10.21883/PJTF.2019.12.47913.17762

Развитие промышленности сопровождается ростом объемов сточных и технологических вод. Качество очистки последних влияет на технологические, экономические, экологические и социальные проблемы. Это способствует интенсивному развитию способов очистки воды от различного рода загрязняющих примесей. Актуальная задача при выборе эффективных способов очистки состоит в необходимости определения качественных (тип) и количественных (концентрация) характеристик загрязняющих веществ. Известна группа способов определения наличия примеси в жидкости, зависящих от типа загрязняющих веществ [1]: органолептические, химические, физико-химические, микробиологические и др. Большое внимание уделяется наличию в воде инородных органических (как правило, растворимых водой) и неорганических примесей, таких как металлы и их производные, частицы глины, ила и прочих твердых включений [1]. Для диагностики такого типа примесей используют химические методы исследований качества воды [1]. Нередко для исследования примесей применяют оптические (рефрактометрический, интерференционный и др.) методы. Главной особенностью таких методик являются их бесконтактность и невозмущающий характер измерений. Интерферометрические методы имеют целый ряд расширений, среди которых исследование размеров оптически прозрачных капель и пузырей [2-4], контроль поверхности тел [5], определение размеров непрозрачных частиц по спекловой картине [6,7] и др. В области же диагностики наличия примеси наибольшее распространение получили исследования содержания растворимых добавок по изменению коэффициента преломления жидкости [8,9]. Известны работы (например, $[10,11])$, в которых выполнен анализ интерференционных и спекловых картин капель с целью определения наличия в последних кристалликов льда. Пока отсутствуют результаты исследований, обосновывающих возможность использования интерферометрической техники для определения характеристик и концентрации твердых частиц в каплях жидкости.

Цель настоящей работы - обоснование возможности исследования типа и концентрации примеси твердых частиц в каплях воды по их интерференционной картине.

Методика проведения эксперимента аналогична использованной в $[10,11]$. С применением малорасходной распылительной форсунки ФМТ-30 генерировался полидисперсный аэрозольный поток с радиусами капель $10-140 \mu \mathrm{m}$ и начальной скоростью движения около $3 \mathrm{~m} / \mathrm{s}$. Поток рассекался в вертикальной плоскости по оси симметрии факела распыла форсунки световым ножом импульсного $\mathrm{Nd}$ : YAG-лазера „Quantel EverGreen $70^{“}$ (длина волны $532 \mathrm{~nm}$, угол раскрытия ножа 22 , толщина ножа $0.2 \mathrm{~mm}$, номинальная мощность в импульсе $37 \mathrm{~mJ}$, частота повторений $4 \mathrm{~Hz}$ ). При попадании капли аэрозоля в плоскость лазерного ножа регистрировалась интерференция (на расфокусированном изображении) между преломленным и отраженным каплей светом [2]. Регистрация интерференционных картин капель осуществлялась видеокамерой „ImperX IGV-B2020M“ (разрешение кадра $2048 \times 2048$ рх, размер регистрационной области $50 \times 50 \mathrm{~mm}$, расстояние от центра регистрационной области до распылительной форсунки $0.19 \mathrm{~m})$, оптическая ось которой была перпендикулярна плоскости лазерного ножа. В комплекте с видеокамерой использовался объектив „Sigma DG $105 \mathrm{~mm}$ f/2.8 EX Масrо“ (расстояние от линзы объектива до области регистрации составило $200 \mathrm{~mm}$, расстояние расфокуси- 

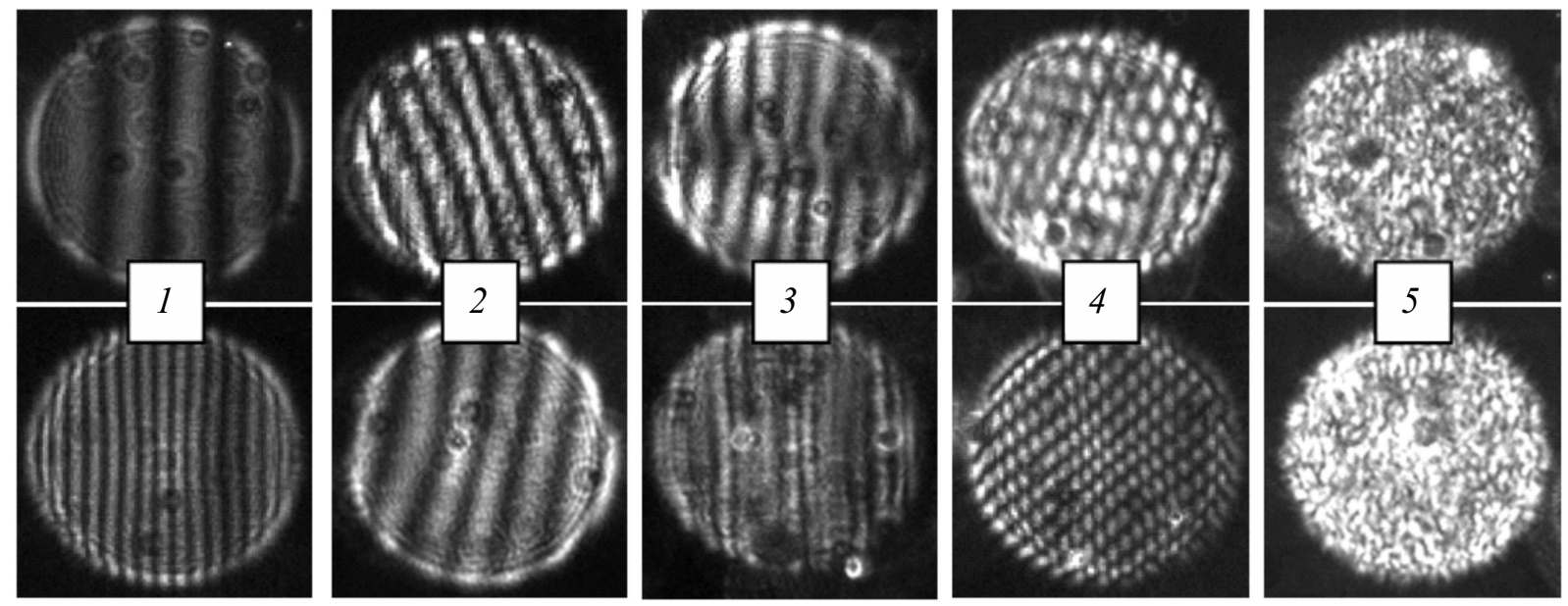

Рис. 1. Интерференционные картины капель, полученные в экспериментах: 1 - нормальная, 2 - угловая, $3-$ кривая, $4-$ гексагональная, 5 - зашумленная.

ровки для последующего получения интерференционной картины около $13 \mathrm{~mm})$.

При проведении экспериментов использовались дистиллированная (ГОСТ 6709-72), водопроводная (ГОСТ Р 51232-98) вода, а также вода с примесью твердых нерастворимых включений. В качестве последних применялись диоксид титана $-\mathrm{TiO}_{2}$ (средний размер частиц $d_{p} \approx 1 \mu \mathrm{m}$, средняя плотность $\left.\rho_{p} \approx 4100 \mathrm{~kg} / \mathrm{m}^{3}\right)$; оксид алюминия $-\mathrm{Al}_{2} \mathrm{O}_{3}\left(d_{p} \approx 3 \mu \mathrm{m}, \rho_{p} \approx 1700 \mathrm{~kg} / \mathrm{m}^{3}\right)$; порошок глины $\left(d_{p} \approx 3.5 \mu \mathrm{m}, \rho_{p} \approx 1300 \mathrm{~kg} / \mathrm{m}^{3}\right)$; полиамидные частицы трех различных размеров $\left(d_{p} \approx 5 \mu \mathrm{m}\right.$, $\rho_{p} \approx 900 \mathrm{~kg} / \mathrm{m}^{3} ; d_{p} \approx 20 \mu \mathrm{m}, \rho_{p} \approx 800 \mathrm{~kg} / \mathrm{m}^{3} ; d_{p} \approx 50 \mu \mathrm{m}$, $\rho_{p} \approx 700 \mathrm{~kg} / \mathrm{m}^{3}$ ). Все используемые типы частиц на длине волны $532 \mathrm{~nm}$ не проявляют видимых абсорбционных свойств. При этом вследствие отсутствия в составе частиц специализированных флуорофоров эмитированный частицами свет также находится на уровне $532 \mathrm{~nm}$. Массовая концентрация примеси в воде варьировалась в диапазоне $G_{m}=0.003-1 \mathrm{~g} / 1$. Примесь взвешивалась лабораторными микровесами „Vibra HT 84RCE“ (дискретность $10^{-5} \mathrm{~g}$ ), после чего смешивалась с необходимым объемом воды. Приготовленный состав заливался в баллон, подключенный к распылительной форсунке, в котором создавалось избыточное давление $10^{5} \mathrm{~Pa}$. Осуществлялись распыление и регистрация образов капель (интерференционных картин). Для каждого состава и каждой концентрации примеси выполнялись три эксперимента, в которых регистрировалось не менее 150 кадров. При этом каждый кадр содержал от 70 до 120 образов. Выводы относительно каждой концентрации примеси делались на основе анализа около 3000 интерференционных картин капель.

В ходе обработки результатов установлены пять видов интерференционных картин капель (рис. 1): 1 - нормальная (характеризуется вертикально расположенными полосами); 2 - угловая (интерференционные полосы расположены под углом к вертикали); 3 - кривая (характеризуется искривленными или невыраженными полосами); 4 - гексагональная (имеет ярко выраженные ромбы или многоугольники, равномерно заполняющие весь образ); 5 - зашумленная (соответствует спекловой картине).

При анализе результатов рассчитывалось интегральное содержание (количество) образов (интерференционных картин) каждого типа

$$
N_{(i)}=n_{i} /\left(n_{1}+n_{2}+\cdots+n_{5}\right) \cdot 100 \%,
$$

где $n_{i}$ - количество образов отдельного типа. Далее строились гистограммы распределения образов капель в потоке (рис. 2). На рис. 2, а приведено содержание образов каждого типа для различных исследованных составов (вертикальные линии на гистограмме соответствуют рассчитанным доверительным интервалам). Первый тип интерференционных картин представляет образ, соответствующий прозрачной сферической капле [2]. Видно, что содержание образов данного типа зависит от типа примеси. Второй тип картин соответствует несферическим каплям, количество образов практически не менялось и во всех экспериментах составляло 4-9\%. Интерес представляют образы третьего, четвертого и пятого типов, так как они обусловливают наличие, концентрацию и тип примеси в капле.

Установлено, что образы четвертого типа зависят главным образом от размера частиц примеси: при неизменном значении $G_{m}$ (рис. $2, a$ ) увеличение $d_{p}$ в диапазоне $1-50 \mu \mathrm{m}$ приводит к росту числа образов данного типа от 3 до 19\%. При этом выполненные эксперименты показывают, что изменение $G_{m}$ незначительно (в пределах 2-3\%) влияет на количество данных картин. Руководствуясь результатами экспериментов, а также значениями $d_{p}$, мы получили зависимость для оценки размеров частиц в капле по содержанию образов четвертого типа

$$
d_{p}=0.6259 \exp \left(0.2171 N_{(4)}\right)[\mu \mathrm{m}] .
$$



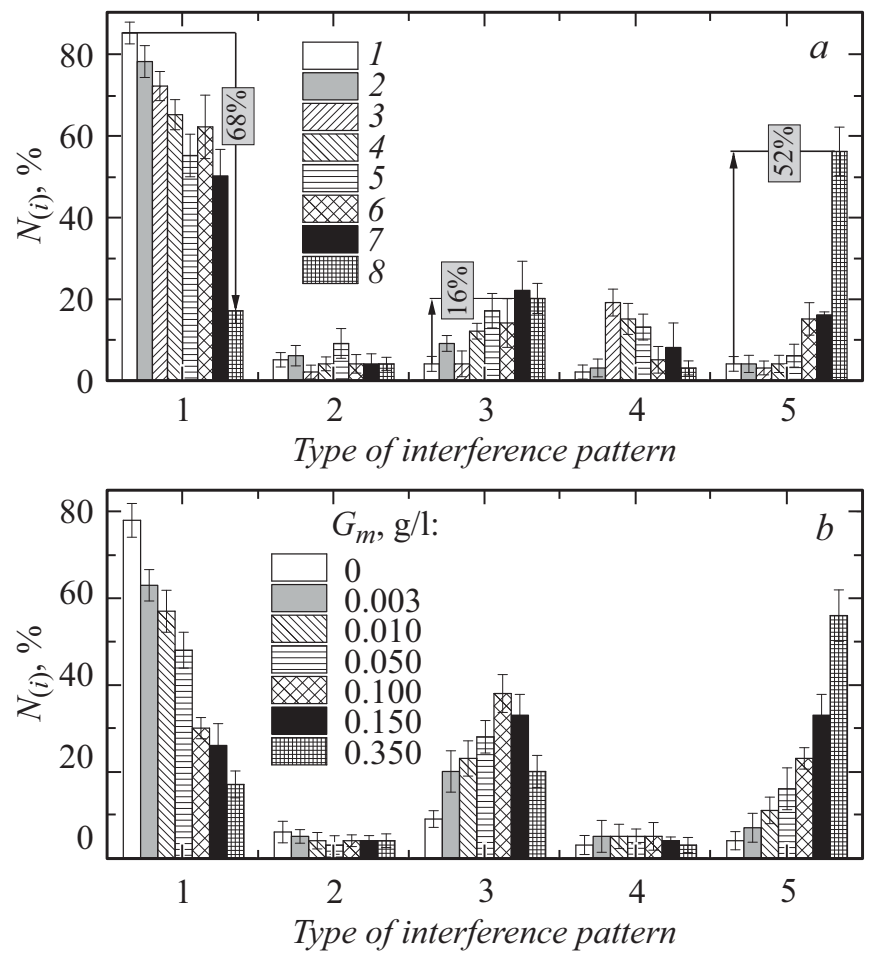

Рис. 2. Содержание $N_{(i)}$ образов пяти выделенных типов в аэрозольном потоке. $a$ - для воды и каждого исследованного состава при $G_{m} \approx 0.35 \mathrm{~g} / \mathrm{l}: 1$ - дистиллированная вода, 2 - водопроводная вода, 3 - полиамидные частицы размером $50 \mu \mathrm{m}, 4$ - полиамидные частицы размером $20 \mu \mathrm{m}, 5$ - полиамидные частицы размером $5 \mu \mathrm{m}, 6-\mathrm{Al}_{2} \mathrm{O}_{3}, 7-$ частицы глины, $8-\mathrm{TiO}_{2} ; b-$ для водопроводной воды с добавлением $\mathrm{TiO}_{2}\left(G_{m}=0-0.35 \mathrm{~g} / \mathrm{l}\right)$.

Опыты показали, что добавление в воду твердых нерастворимых частиц приводит к увеличению числа образов третьего и пятого типа. С ростом $G_{m}$ их количество значительно (в несколько раз) увеличивается. Так, например, для примеси $\mathrm{TiO}_{2}$ (рис. $2, b$ ) количество образов третьего и пятого типов может возрастать в десятки раз по сравнению с водой, что служит интегральным показателем наличия примеси в каплях. Зарегистрировано, что при определенных значениях $G_{m}$ прослеживаются снижение числа образов третьего типа и существенный рост количества образов пятого типа (предельная концентрация, приводящая к образованию спекловых картин). Для примеси $\mathrm{TiO}_{2}$ эти значения соответствуют $G_{m}=0.1-0.15 \mathrm{~g} / 1$, для $\mathrm{Al}_{2} \mathrm{O}_{3} \quad G_{m}=0.7-0.8 \mathrm{~g} / 1$, для частиц глины $G_{m}=0.8-1 \mathrm{~g} / 1$. Иными словами, чем крупнее средний размер частиц примеси, тем выше значения $G_{m}$.

С целью обобщения полученных результатов построены зависимости $N_{(3+5)}=f\left(G_{m}\right)$ (рис. $\left.3, a\right)$. Видно, что значения $N_{(3+5)}$ для одних и тех же $G_{m}$ существенно различаются. Последнее связано со средним размером частиц $d_{p}$. Очевидно, что тип полученной интерференционной картины (рис. 1) зависит от числа частиц в капле, попавших в плоскость лазерного ножа. Однако при разных значениях $\rho_{p}$ и $d_{p}$ данное число может различаться на несколько порядков. Как следствие, целесообразно вместо массовой $\left(G_{m}\right)$ использовать количественную $\left(G_{q}\right)$ концентрацию частиц

$$
G_{q}=G_{m} /\left(\rho_{p}(4 / 3) \pi\left(d_{p} / 2\right)^{3}\right)\left[1^{-1}\right]
$$

Параметр $G_{q}$ иллюстрирует количество частиц в одном литре воды. На рис. $3, b, c$ приведены зависимости типа $N_{(3+5)}=f\left(G_{q}\right)$ и $N_{(1)}=f\left(G_{q}\right)$. Видно, что в данном случае полученные результаты хорошо коррелируют между собой. Значения $G_{q}$ также могут быть определены по количеству образов первого типа (рис. $3, b$ ). Такой подход является менее точным, так как не учитывает образы четвертого типа. Однако он значительно упрощает вычислительный процесс. Для определения параметра $G_{q}$ по содержанию отдельных образов (рис. $3, b, c$ )
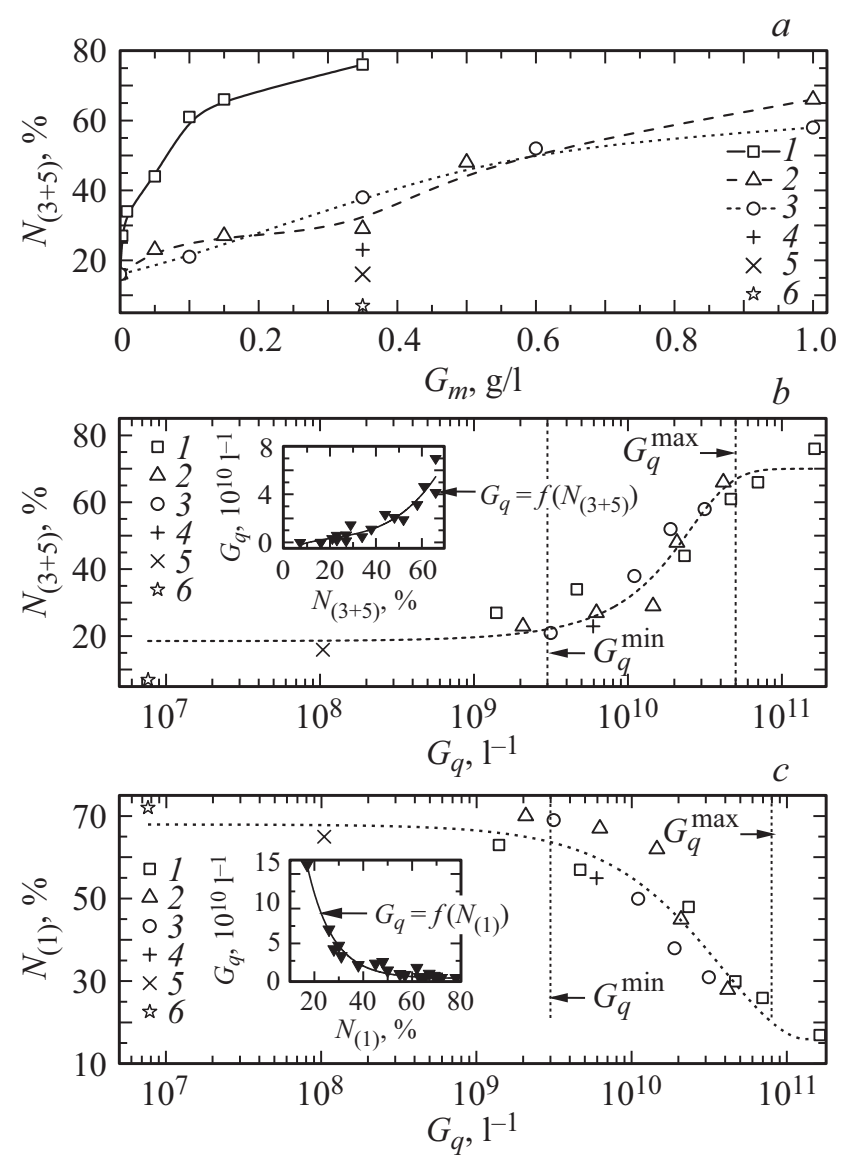

Рис. 3. Зависимость содержания $N_{(3+5)}$ образов третьего и пятого типов от массовой $G_{m}(a)$ и количественной $G_{q}(b)$ концентрации частиц примеси в воде, а также зависимость содержания $N_{(1)}$ образов первого типа от количественной концентрации $G_{q}$ частиц примеси в воде $(c) .1-\mathrm{TiO}_{2}$, $2-\mathrm{Al}_{2} \mathrm{O}_{3}, 3$ - частицы глины, 4 - полиамидные частицы размером $5 \mu \mathrm{m}, 5$ - полиамидные частицы размером $20 \mu \mathrm{m}$, 6 - полиамидные частицы размером $50 \mu \mathrm{m}$. 
получены аппроксимационные зависимости

$$
\begin{gathered}
G_{q}=-6.81699 \cdot 10^{9}+8.58538 \cdot 10^{8} N_{(3+5)} \\
-2.59886 \cdot 10^{7} N_{(3+5)}^{2}+4.10951 \cdot 10^{5} N_{(3+5)}^{3}\left[1^{-1}\right] \\
G_{q}=-4.67861 \cdot 10^{8}+8.36818 \cdot 10^{11} \\
\times \exp \left(-0.09602 N_{(1)}\right)\left[1^{-1}\right]
\end{gathered}
$$

При использовании выражений (2) и (3) следует учитывать, что они могут быть применены для прогнозирования $G_{q}$ в диапазоне от $G_{q}^{\min }$ до $G_{q}^{\max }$ (рис. $\left.3, b, c\right)$, так как за пределами этих значений практически не наблюдается существенного изменения количества соответствующих интерференционных картин капель. Экспериментально установлено, что в первом приближении этот диапазон соответствует $G_{q}=3 \cdot 10^{9}-5 \cdot 10^{10} 1^{-1}$ для $N_{(3+5)}$ (рис. $\left.3, b\right)$ и $G_{q}=3 \cdot 10^{9}-8 \cdot 10^{10} 1^{-1}$ для $N_{(1)}$ (рис. $3, c)$.

В заключение следует подчеркнуть, что по результатам выполненных исследований впервые предпринята попытка диагностики типа и концентрации частиц твердой примеси в каплях водяного аэрозоля по их интерференционной картине. Такой интерференционный анализ позволяет по содержанию образов прогнозировать размеры частиц и их количественную концентрацию в каплях (по формулам (1)-(3)). Результаты выполненного цикла экспериментов способствуют развитию современных методов диагностики твердых нерастворимых примесей в жидкости $[1,6,7,10,11]$, а также потенциально способствуют разработке перспективных газопарокапельных технологий, в частности в области термической очистки жидкостей.

\section{Финансирование работы}

Исследование выполнено при финансовой поддержке Российского фонда фундаментальных исследований в рамках научного проекта № 18-38-00007 мол_а.

\section{Конфликт интересов}

Авторы заявляют, что у них нет конфликта интересов.

\section{Список литературы}

[1] Нефедова Е.Д. Методы и технические средства мониторинга, контроля качества воды в местах водозаборов и управление технологическим процессом водоподготовки в условиях изменения качества воды поверхностных водоисточников. Канд. дис. СПб.: Сев.-Зап. гос. заоч. техн. Ун-т, 2010. $308 \mathrm{c}$.

[2] Бильский А.В., Ложккин Ю.А., Маркович Д.М. // Теплофизика и аэромеханика. 2011. Т. 18. № 1. С. 1-13.

[3] Волков Р.С., Кузнецов Г.В., Стрижак П.А. // Письма в ЖТФ. 2016. Т. 42. В. 12. C. 73-81.

[4] Maeda M., Kawaguchi T., Hishida K. // Meas. Sci. Technol. 2000. V. 11. N 12. P. L13-L18.
[5] Жижин Г.Н., Никитин А.К., Рыжова Т.А., Логинов А.П. // Письма в ЖТФ. 2004. Т. 30. В. 21. С. 88-94.

[6] Ruiz S.G., Beeck J. // Exp. Fluids. 2017. V. 58. N 8. P. 100.

[7] Павлов П.В., Астахов М.О., Манучаров Д.Р. // Информатика: проблемы, методология, технологии. Материалы XVIII Междунар. научн.-метод. конф. Воронеж: Научноисследовательские публикации, 2018. Т. 4. С. 189-194.

[8] Mahdieh M.H., Nazari T. // Optic. 2013. V. 124. N 20. P. 4393-4396.

[9] Kachiraju S.R., Gregory D.A. // Opt. Laser Technol. 2012. V. 44. N 8. P. 2361-2365.

[10] Brunel M., Talbi M., Coetmellec S., Grehan G., Wu Y., Kielar J.J. // Opt. Commun. 2019. V. 433. P. 173-182.

[11] Kielar J.J., Wu Y., Coëtmellec S., Lebrun D., Gréhan G., Brunel M. // J. Quant. Spectr. Rad. Transfer. 2016. V. 178. P. $108-116$. 